\title{
Featural and configural face processing in adults and infants: A behavioral and electrophysiological investigation
}

\section{Citation}

Scott, Lisa S, and Charles A Nelson. 2006. "Featural and Configural Face Processing in Adults and Infants: A Behavioral and Electrophysiological Investigation." Perception 35 (8): 1107-1128. doi:10.1068/p5493.

\section{Published Version}

doi:DOI:10.1068/p5493

\section{Permanent link}

http://nrs.harvard.edu/urn-3:HUL.InstRepos:13548962

\section{Terms of Use}

This article was downloaded from Harvard University's DASH repository, and is made available under the terms and conditions applicable to Other Posted Material, as set forth at http:// nrs.harvard.edu/urn-3:HUL.InstRepos:dash.current.terms-of-use\#LAA

\section{Share Your Story}

The Harvard community has made this article openly available.

Please share how this access benefits you. Submit a story.

\section{Accessibility}




\title{
Featural and configural face processing in adults and infants: A behavioral and electrophysiological investigation
}

\author{
Lisa S Scott \\ Department of Psychology, University of Massachusetts, Amherst, MA 01003, USA; \\ e-mail: Iscott@psych.umass.edu
}

\section{Charles A Nelson}

Institute of Child Development [also Center for Cognitive Sciences, Center for Neurobehavioral Development, Department of Pediatrics], University of Minnesota, Minneapolis, MN 55455, USA Received 14 October 2004, in revised form 28 February 2005; published online 9 June 2006

\begin{abstract}
We sought to elucidate the behavioral and electrophysiological correlates of face processing, in adults and infants, by manipulating either the featural or configural information within the face. Two different experiments are reported. In these experiments, event-related potentials (ERPs) were recorded from the scalp while adult, 8-month-old, and 4-month-old participants completed configural-change and featural-change face tasks. The infants also completed a behavioral visual paired-comparison task with featural and configural face changes. ERP results reveal hemispheric differences in processing featural but not configural changes for the N170 in adults. Furthermore, featural and configural changes are processed differently within the right and left hemispheres. The right hemisphere N170 is significantly greater for configural compared to featural changes. The left hemisphere N170, however, exhibits the opposite effect. Infant data suggest that similar to adults, 8-month-old, but not 4-month-old participants, exhibit similar hemispheric differences between featural and configural changes for the P400 component. Behavioral results suggest increased sensitivity to both featural and configural face changes in 8-month-olds compared to 4-month-olds.
\end{abstract}

\section{Introduction}

A recent model of the development of face recognition posits that infants mold their face processing system on the basis of exposure to the specific kinds of faces they encounter (Nelson 2001, 2003). Such exposure, in turn, leads to cortical specialization, and eventually, a narrowing of the perceptual window through which faces are perceived. With development, then, comes an improved sensitivity when recognizing the most commonly experienced faces and a lack of sensitivity when recognizing and discriminating less commonly experienced faces. Support for this theory comes from research on the 'other-race' and 'other-species' effects, as well as research on perceptual expertise. For example, the 'other-race' effect is a common experience in which people report more difficulty differentiating between two faces of another race compared to two faces within one's own race (Chance et al 1982). Similarly, Pascalis and colleagues report that 6-month-old infants are better at discriminating monkey faces than are 9-monthold infants and adults (Pascalis et al 2002). Furthermore, experience with monkey faces (sending infants home with a monkey picture book from 6 to 9 months of age) can influence the specificity of this system (Pascalis et al 2005). More specifically, results of this study indicate that infants who are given experience with monkey faces sustain the ability to discriminate monkey faces at 9 months of age. Combined, these results support the importance of perceptual learning about faces, occurring early in development, but the nature and mechanisms influencing this learning are not well specified.

Nelson $(2001,2003)$ hypothesized a decrease, with development, in the ability to differentiate faces not commonly present in one's perceptual environment. However, it is currently unclear what accounts for this decrease. One possible mechanism is the development of configural or holistic face processing. Configural processing is typically 
defined as the ability to process faces or objects as a whole. However, configural processing is not a unitary construct, and thus there are many definitions and several different types of configural face processing. For purposes of the current study, configural face processing refers to the spatial layout of face elements and their relation to one another (what has been referred to as second-order configural processing). Featural information within a face, however, includes the individual elements that can be referred to in relative isolation (such as the eyes, or mouth). These sources of information are not mutually exclusive, as featural changes necessitate a change in configuration, and changes in configurations involve a concomitant change in the individual features (Tanaka and Sengco 1997). Configural processing is considered a hallmark of face processing relative to processing other perceptual stimuli, such as objects (Carey and Diamond 1977; Sergent 1984; Rhodes 1988; Rhodes et al 1993; Farah et al 1995; McKone et al 2001; Murray et al 2003). The human reliance on configural information in the recognition and processing of faces is demonstrated when faces are inverted (Yin 1969) and also when features of inverted faces are upright (Thompson 1980). Inversion tends to impair recognition of faces more than of objects. This effect was first reported by Yin (1969) who found that inversion disrupts the configural processing of a face. Furthermore, Farah et al (1995) contend that faces are represented as holistic units, whereas objects can be broken down into separable parts. Inverting a face presumably causes a disruption in this configural or holistic processing, and thus causes decrements in face processing, such as impaired recognition, and delayed reaction time (Freire et al 2000). Interestingly, individuals with specific face recognition deficits (those with prosopagnosia), exhibit performance advantages over normal controls on inverted face processing (Farah 1995; de Gelder et al 1998). Marotta et al (2001) conducted an fMRI study with prosopagnosic patients and found that these patients did not show the normal pattern of activation of the fusiform area. They did, however, report left-hemisphere posterior fusiform activation, which, according to the authors, suggests that these patients are processing stimuli in a more feature-based than holistic manner.

It is currently unclear why there is this bias for processing faces configurally. Moreover, it is unclear how configural processing of faces develops and changes over time. Several recent investigations suggest that configural processing may go hand in hand with expert perceptual processing. For example, Gauthier and Tarr (1997) report that participants who were trained to be experts at identifying and differentiating greebles (a category of objects, designed to be similar to faces), tend to be more impaired when the configural information of these stimuli is disrupted after training. Furthermore, car experts are impaired at identifying cars when the configuration of a car is disrupted (Gauthier et al 2003). This experience-based explanation is consistent with developmental data suggesting that 9-year-old patients with bilateral congenital cataracts removed between 2 and 6 months of age are impaired in configural face processing (but not featural face processing) relative to typically developing controls (Le Grand et al 2001). Thus, visual experience with faces early in development (first 6 months of life) may be important for the development of configural face processing.

Other developmental investigations also suggest that changes in infants' abilities to process stimuli configurally occur within the first year of life. These findings suggest that there may be a shift (or multiple shifts) from featural to configural processing in infancy (Younger and Cohen 1986; Cohen and Cashon 2001; Le Grand et al 2001; Cashon and Cohen 2004). For example, Younger and Cohen (1986) investigated the ability of infants aged 4, 7, and 10 months to process the correlations among features of schematic drawings of imaginary animals. Results indicated that 7-month-olds but not 4-month-olds, responded to the animal picture holistically. Furthermore, Kestenbaum and Nelson (1990) showed that 7-month-old infants could form a category of the facial 
expression happiness if the faces were upright but not if the faces were inverted, suggesting that, similar to adults, 7-month-olds process upright faces holistically and inverted faces using featural information. Cohen and Cashon (2001) report a developmental shift from featural to configural processing of faces. They suggest that before the age of 7 months, infants process specific features of complex objects but after the age of 7 months they are able to integrate those features into a whole object. Furthermore, when faces were upright, but not inverted, 7-month-old infants looked longer at the face with switched internal features than at the familiar face. In a follow-up investigation, Cashon and Cohen (2004) suggest that the development of configural processing, based on inversion effects, may follow an $\mathrm{N}$-shaped developmental course from 3 to 7 months of age. More specifically, these authors report that there may be two shifts from featural to configural processing of faces, the first occurring between 3 and 4 months of age and the second occurring between 6 and 7 months of age.

The current set of experiments was designed to elucidate the development of configural and featural face processing in adults and infants by recording event-related potentials (ERPs) and comparing results across ages. Although one cannot completely dissociate featural and configural face processing, the stimuli used in the current experiment were designed to differentially weight these two types of changes. For example, noticing that the eyes of a face have been moved should preferentially tap configural processing compared to when the eyes of the same face have been replaced with different eyes (this type of change should preferentially tap featural processing). Participants across all ages were presented with faces with either featural or configural changes while ERPs were recorded from the scalp.

\section{Experiment 1: Configural and featural face processing in adults}

Several neuroimaging methods have been used to study the functional neuroanatomy of face processing. The fusiform face area (FFA), an area in the ventral occipitotemporal cortex, has been identified as being disproportionately active during the presentation of faces or face-like stimuli (Kanwisher et al 1997; Haxby et al 2001). Studies using ERPs have found a negatively peaked component occurring around $170 \mathrm{~ms}$ (N170) after stimulus onset that differentiates faces and objects (eg Bentin et al 1996; Jeffreys 1996; Carmel and Bentin 2002). This negative component tends to be prominent over lateral leads (eg Carmel and Bentin 2002; de Haan et al 2002); it does not appear to be sensitive to familiar versus unfamiliar faces (Bentin and Deouell 2000); is enhanced and delayed by stimulus inversion (Rossion et al 1999, 2000; Sagiv and Bentin 2001); and can be elicited by schematic drawings (Sagiv and Bentin 2001) and isolated facial features (eyes) (Bentin et al 1996). Moreover, the context of the task used also does not appear to influence the response of this component (Carmel and Bentin 2002). These results suggest that the N170 response may be somewhat domain-specific. However, in several recent investigations N170 modulations have been found in response to the presentation of objects of expertise (Tanaka and Curran 2001; Curran et al 2002; Rossion et al 2002) This electrophysiological modulation may be due to an increase in configural processing with increases in perceptual expertise (Rossion et al 2002; Gauthier et al 2003; Tanaka et al 2004). For example, inverting objects (disrupting configural processing) in which participants have obtained expertise (eg greebles) results in a larger and longer latency to peak N170 in the left hemisphere (Rossion et al 2002).

To date, no direct electrophysiological comparison of featural and configural face processing has been completed. An understanding of the processing biases and electrophysiological differences between configural and featural face processing may further elucidate the function of the N170 component. Currently there are two main competing hypotheses for the function of the N170: a domain-specific and a domain-general hypothesis. The domain-specific explanation suggests that the N170 is specific to faces 
(eg Carmel and Bentin 2002), and the domain-general hypothesis suggests that the N170 is involved in processing and categorizing objects of expertise (eg Tanaka and Curran 2001). In the current investigation, we sought to further investigate the function of the $\mathrm{N} 170$ in adults. If the N170 does not differentiate configural and featural changes to faces, a domain-specific hypothesis would be supported (ie the N170 is a 'face detector' that is not sensitive to configural and featural manipulations). However, if the N170 is modulated by a more general mechanism, including perceptual expertise and configural processing, manipulations of the information should influence the N170. More specifically, we would expect to see N170 amplitude and latency differences in detecting both configural and featural face changes. In the current study, we further investigated these alternative explanations by presenting adult participants with changes in configural and featural information while ERPs were recorded.

\subsection{Methods}

2.1.1 Participants. The University of Minnesota Institutional Review Board approved all procedures used in this study. Informed consent was obtained from all participants. Participants were fourteen healthy right-handed adults (eight female), recruited from the undergraduate population at the University of Minnesota. An additional two participants were excluded owing to excessive eye or movement artifacts. Participants were either paid $\$ 10$ or given extra credit for an Introductory Psychology class. All participants were Caucasian.

2.1.2 Stimuli. Stimuli included gray-scale faces that were changed in one of two ways - either configurally or featurally. All stimulus changes were made with Adobe Photoshop (version 5.5). Faces were altered by either moving or replacing the eyes or the mouth (see figure 1). Each face measured $28 \mathrm{~cm}$ (diagonally). For the configural changes, the eyes were moved approximately $\frac{3}{4}-1 \mathrm{~cm}$ away from their original position, and the mouth was moved approximately $\frac{1}{2}-\frac{3}{4} \mathrm{~cm}$ down from its original position. For the featural changes, the eyes and the mouth were replaced with someone else's eyes or mouth without changing the location of the features.

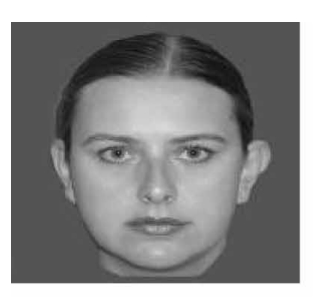

Featural change
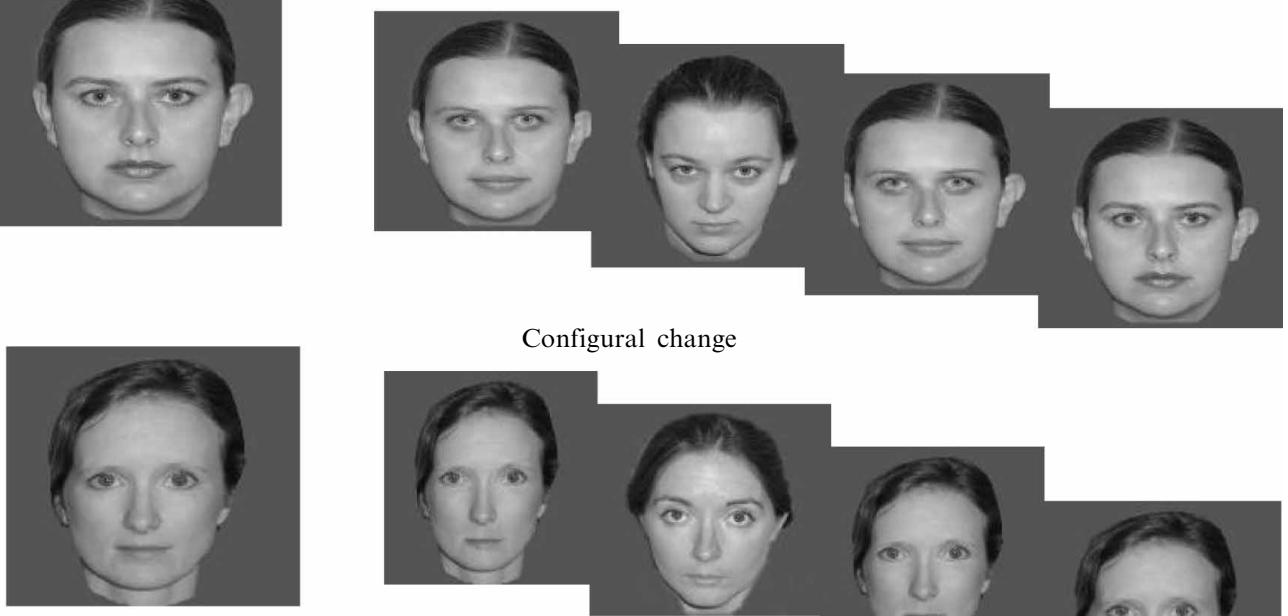

Configural change

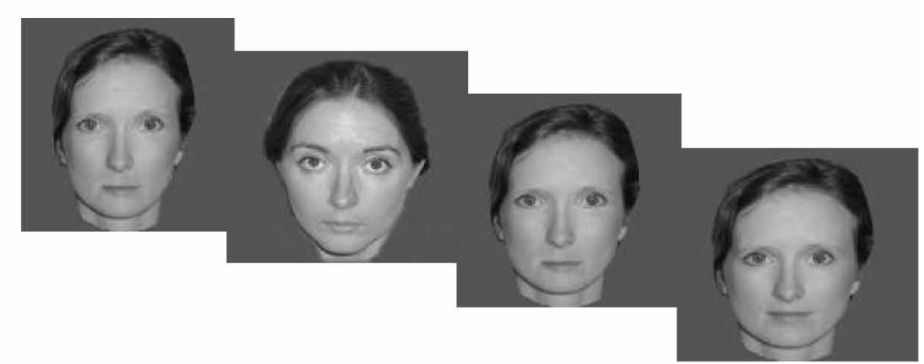

Familiarization $\longrightarrow$ Test (serially presented)

Figure 1. Experiment 1: Example of stimuli and procedure used while event-related potentials were collected from adults and infants. 
On the basis of the results of pilot testing, the faces used in this experiment were matched for level of difficulty (see figure 1). In this pilot test, participants simply indicated whether two side-by-side faces were the same picture or a different picture. The side-by-side presentations included configural and featural changes as well as comparisons of faces that were the same. Accuracy and reaction-time measures were used to identify configural and featural changes in faces that were relatively equivalent in difficulty to detect the change. These faces were then used in the present investigation. Thus, detecting configural and featural changes across these faces was equivalent. Stimuli were presented with E-prime (version 1.0). Stimuli consisted of 180 randomly presented trials of each of 3 conditions (60 trials of each condition). The presentation of stimuli included the following: (i) the familiarized unchanged face, (ii) the familiarized face with either its features or its configuration altered, and (iii) a novel face (see figure 1). These stimuli did not change throughout the paradigm and there was only one image for each condition. Each stimulus was presented for $500 \mathrm{~ms}$, with a varying inter-trial interval of $1200-1300 \mathrm{~ms}$. All stimuli were presented on a blue screen. After the inter-trial interval, a white fixation cross was presented for $500 \mathrm{~ms}$ prior to the presentation of the next stimulus.

2.1.3 Procedure. Participants were seated approximately $60-70 \mathrm{~cm}$ away from the computer monitor and the visual angle subtended by the stimuli was $13.30 \mathrm{deg}$. Adults completed both a configural-change and a featural-change face task (within-subjects; order was counterbalanced). Adults were familiarized with a single unfamiliar unchanged face. They were told to press a button when they had memorized the face well enough to identify it in subsequent trials, if needed (average exposure of $38 \mathrm{~s}$ ). Adults then passively viewed a series of serially presented faces while ERPs were recorded. Participants were instructed not to move and to try not to blink. During the experiment, a researcher viewed a live video of participants while they completed both tasks. Participants were informed that they would be monitored by video. If participants appeared to be inattentive, the experimenter asked them to be more attentive.

2.1.4 Electrophysiological methods. ERPs were collected with a 128-channel Geodesic Sensor Net (Electrical Geodesics, Inc., Eugene, Oregon) connected to an AC-coupled 128-channel, high-input-impedance amplifier (Net Amps 200, Electrical Geodesics, Inc.). Amplified analog voltages $(0.1-100 \mathrm{~Hz}$ bandpass $)$ were digitized at $250 \mathrm{~Hz}$. Impedances were accepted if they were less than $50 \mathrm{k} \Omega$.

Post-recording segmentation and averaging was completed with Netstation 4.01 (Electrical Geodesics, Inc.). Trials were discarded from analyses if they contained vertical eye movements (vertical EOG channels greater than $70 \mu \mathrm{V}$ ) or more than 10 bad channels (changing more than $100 \mu \mathrm{V}$ between samples or if amplitudes exceeded $200 \mu \mathrm{V}$ ). Individual channels that were consistently bad (offscale on more than $20 \%$ of the trials) were replaced with the use of a spherical interpolation algorithm. A mean of 2.6 channels were replaced with interpolated data per participant.

Participants' ERPs were segmented and averaged to six different conditions including featural task: (i) familiarized face, (ii) featural change, (iii) unfamiliar face; and configural task: (iv) familiarized face, (v) configural change, (vi) unfamiliar face. Difference waves were computed by subtracting the waveform response of configural and featural changes from the familiarized face in each task. Two participants with fewer than 20 artifact-free trials per condition were excluded from analyses. The mean number of trials included in each condition across all subjects ranged from $42-48$. ERPs were baseline corrected with respect to a $100-\mathrm{ms}$ pre-stimulus recording interval and were digitally low-pass filtered at $30 \mathrm{~Hz}$. An average reference was used to minimize the effects of reference site activity and accurately estimate the scalp topography of ERPs recorded from a high-density electrode montage (Dien 1998). 


\subsection{Results}

Analyses for the present study focused on the N170 component. Maximum negative amplitude and the corresponding latency were analyzed across conditions from 143 to $219 \mathrm{~ms}$ after stimulus onset. The channels selected for analyses were determined on the basis of previous reports of the N170 obtained with the EGI system (for example, see Tanaka and Curran 2001) and by identifying the electrode locations within the occipital-temporal regions with prominent N170 components. Six electrodes from each hemisphere were then averaged (left $=59,60,51,58,52$, and 65; right $=92,93$, 86, 91, 97, and 98). Two different types of analyses were conducted. Amplitude and latency measures were first submitted to a $2 \times 3 \times 2$ MANOVA with two levels of task or condition (configural; featural), three levels of type (familiarized face; unfamiliar face; familiarized face with either a configural or featural change), and two levels of hemisphere (right; left) to determine overall effects. Analyses were also conducted on difference waves. Difference waves were calculated by subtracting the response to the altered face from the response to the original unaltered face for both the featural and configural conditions. Amplitude and latency measures for the difference-wave analyses were submitted to a $2 \times 2$ MANOVA with two levels of condition (configural difference; featural differences) and two levels of hemisphere (right; left). Significant main effects and interactions were followed up with paired comparisons corrected for multiple comparisons.

2.2.1 Overall electrophysiological results. Overall amplitude analyses did not reveal any significant main effects or interactions for the N170 component. For latency measures, there were no significant main effects, but there was a significant interaction between condition and type of trial $\left(F_{2,12}=4.33, p<0.05\right)$. Follow-up $t$-tests indicate that the latency response to the unfamiliar face was different, depending on whether the faces were presented in the configural or featural task. The unfamiliar face in the featural task peaked at a significantly later latency than the unfamiliar face in the configural task $\left(t_{13}=-2.42, p<0.05\right)$.

2.2.2 Difference-wave results. Difference waves were computed by subtracting the N170 response to the altered face from that to the familiarized (unaltered) face (either configural or featural changes). Amplitude results indicate no main effects of condition or hemisphere, but there was a significant interaction between condition (configural/ featural $)$ and hemisphere $\left(F_{1,13}=12.38, p<0.01\right)$. Follow-up tests indicate a greater difference between the featural change and the original faces in the left hemisphere than in the right hemisphere $\left(t_{13}=-3.66, p<0.01\right)$. There was no difference between the configural change and the original face across hemispheres. Additionally, the difference in the left hemisphere was significantly greater for the featural than for the configural changes $\left(t_{13}=-2.21, p<0.05\right)$, and the difference in amplitude in the right hemisphere was greater for configural than for featural changes $\left(t_{13}=2.39, p<0.05\right.$; see figures 2 and 3 ; table 1). There were no significant latency effects.

Table 1. Significant main effects (means with standard errors in parentheses) for the difference-wave amplitude measures of the N170 in adults.

Difference Left hemisphere Right hemisphere

Featural $/ \mu \mathrm{V} \quad-1.33(0.267)^{*}, * *-0.21(0.231) *, * *$

Configural $/ \mu \mathrm{V} \quad-0.70(0.264) * \quad-1.25(0.352) *$

$* p<0.05$ (single asterisk denotes comparisons between configural and featural conditions within hemispheres); ${ }^{* *} p<0.01$ (double asterisk denotes comparisons across hemispheres within a condition). 


\subsection{Discussion}

The current study was designed to elucidate the electrophysiological correlates of featural and configural processing. Results of the overall amplitude and latency effects across both configural and featural tasks revealed no amplitude or latency differences when participants viewed the familiarized face, the unfamiliar face, and the altered familiarized face within each task (configural or featural). These findings are consistent with several past reports that suggest that the N170 is a 'face detector' and is not sensitive to changes across faces (Bentin et al 1996; Bentin and Deouell 2000; Sagiv and Bentin 2001; Carmel and Bentin 2002). However, the context of the task (either configural or featural) appears to have influenced the role of the unfamiliar face. The latency of the N170 component was significantly longer for the unfamiliar face in the featural than in the configural task. These data suggest that, contrary to what others have reported (Carmel and Bentin 2002), the latency of the N170 may be influenced by the task context. Interestingly, results of the difference-wave analyses (subtracting the N170 response to the altered face from that to the original familiarized face) reveal important differences between configural and featural processing, suggesting that the N170 is influenced by changes in the configural and featural information within a face. Specifically, hemispheric differences were found across these different types of changes; the N170 is greater in the left hemisphere than in the right hemisphere for featural changes. Additionally, featural and configural changes are processed differently within the right and left hemispheres. The right-hemisphere N170 is significantly greater for configural than for featural changes. The left-hemisphere N170, however, exhibits the opposite effect. These data suggest that, similar to what has been reported in studies with fMRI (Marotta et al 2001), PET (Rossion et al 2000), in developmental studies (Deruelle and de Schonen 1998), in prospagnosic patients (de Renzi et al 1994), and in patients with left monocular deprivation due to congenital cataracts (Le Grand et al 2003), there are hemispheric differences between configural and featural processing. Unlike some of the previous investigations, we found that featural processing appears to be more lateralized (left) than configural processing.

These hemispheric differences are also consistent with previously reported hemispheric differences between global and local processing. For example, Akshoomoff et al (2002) looked at the impact of early unilateral brain injury on perceptual organization and visual memory. In that study, patients with right-hemisphere and left-hemisphere damage were asked to copy a complex figure. Findings indicated that children with right-hemisphere damage attended mostly to details and children with left-hemisphere damage attended mostly to the larger configuration.

Overall, the results of this study suggest that, although N170 differences between configural and featural face processing are negligible at first glance, differences emerge when compared to the original familiarized face (in the absence of the unfamiliar face). These results suggest that the N170 can be influenced by changes in task context and is sensitive to changes in both configural and featural information within a face. Furthermore, these data reveal a dissociation between configural and featural processing within the right and left hemispheres, suggesting that featural changes elicit a larger N170 in the left hemisphere and configural changes elicit a larger N170 in the right hemisphere.

\section{Experiment 2: Configural and featural face processing within the first year of life}

Although there is a growing literature documenting the properties of the face-sensitive N170 in adults, we have only recently begun to study the infant analog to this component. The infant N290 and the P400 have been identified as being modulated by faces in a similar manner as the adult N170. Between 7 and 12 months of age the infant N290 component is modulated by stimulus inversion in the same way as the adult 

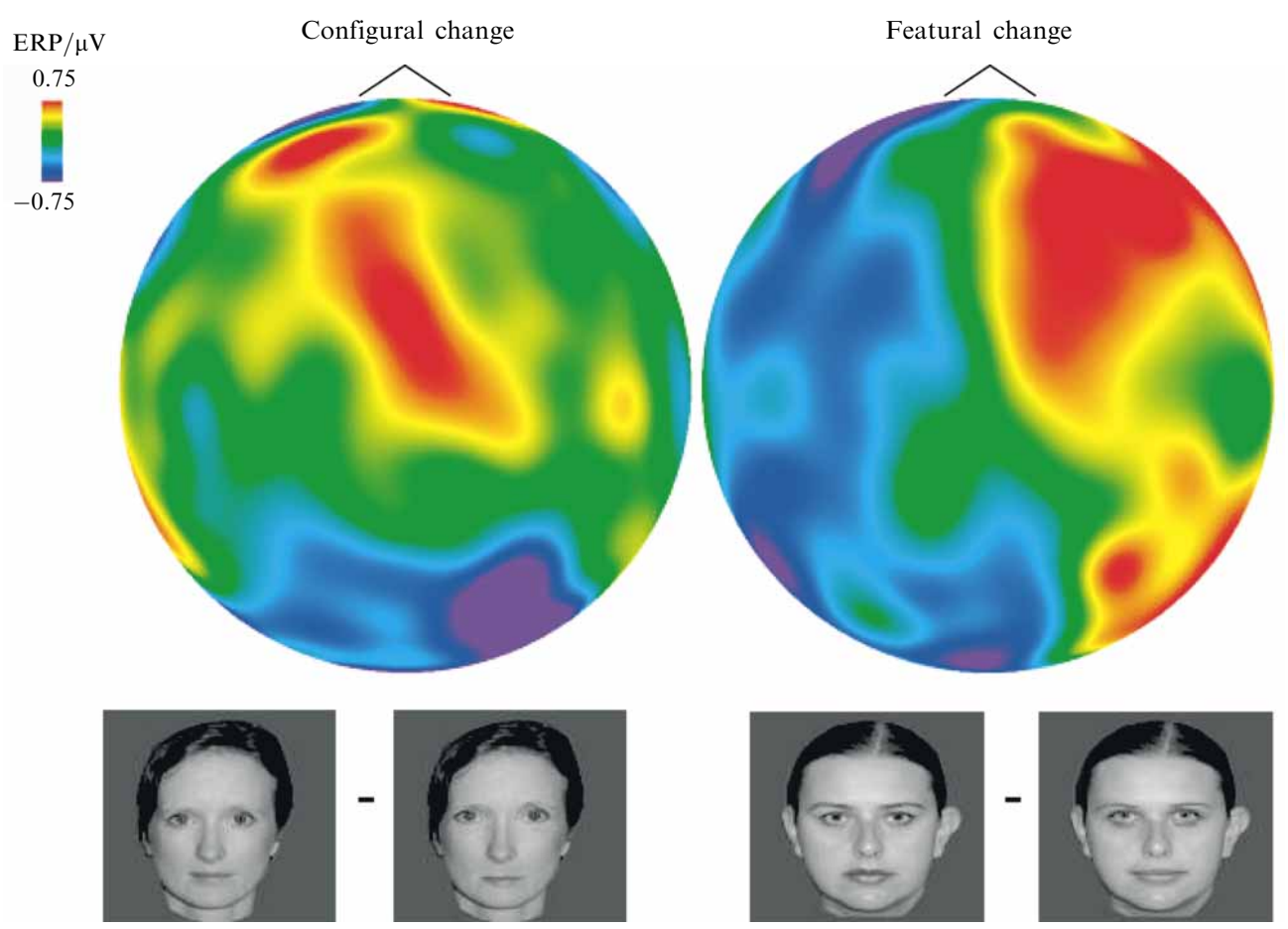

Figure 2. Experiment 1: Topographic differences between configural and featural changes for the N170 in adults. Topographic maps represent the difference between the original familiarized face and faces with either the featural change or configural change.
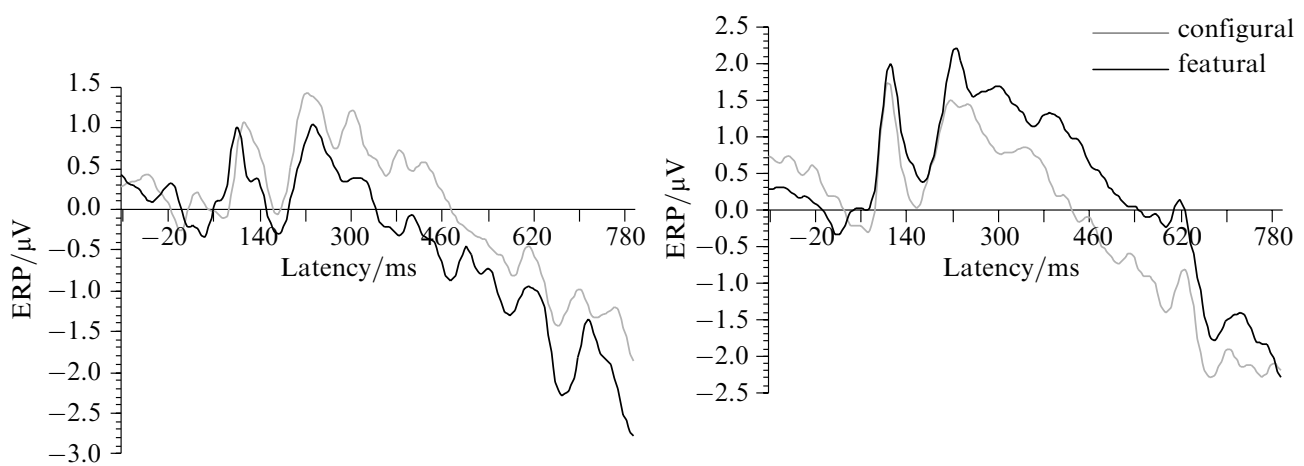

Figure 3. Experiment 1: Morphology of ERP waveform in adults. The left hemisphere graph (a) represents an average of electrodes: $59,65,60,58$, and 51 across both the configural and featural change conditions. The right hemisphere graph (b) represents an average of electrodes: 92, 93, 86, 97, 91, and 85. Please note amplitude scale differences.

N170 (de Haan et al 2002; Halit et al 2003). However, 3-month-olds and 6-month-olds do not show stimulus inversion for the N290 but do show inversion effects for the later P400 component (de Haan et al 2002; Halit et al 2003). Additionally, although the P400 is opposite in polarity and occurs at a later latency than the adult N170, it does respond faster to faces than to objects (de Haan and Nelson 1999).

The purpose of the present study was twofold. First, this experiment was designed to investigate the reported developmental progression from featural to configural processing of faces in infants by both behavioral (the visual paired-comparison procedure) and electrophysiological measures. Second, this investigation further elucidates the relation of 
the infant N290 and P400 face components to the adult N170 component. Four groups of infants, two groups of 4-month-olds and two groups of 8-month-olds, completed both a behavioral visual paired-comparison task as well as an infant controlled habituation of a single face, followed by a presentation of the familiar face with alterations made to it and of a novel face while ERPs were recorded. These age groups were chosen to test the shifts observed from 3 to 7 months of age (Cohen and Cashon 2001; Cashon and Cohen 2004) and the reported importance of the first 6 months of visual experience (Le Grand et al 2001). If there is a shift from featural to configural processing from 4 to 8 months of age, 8 -month-olds may be more sensitive to changes in configurations (both behaviorally and as indexed in the infant N290 and P400 ERP components) than 4-month-olds. Additionally, if 8-month-olds are using more adult-like modes of processing, we expect to demonstrate more similarities between ERP components in 8-month-olds and adults relative to adults and 4-month-olds.

\subsection{Methods}

3.1.1 Participants. The University of Minnesota Institutional Review Board approved all methods and procedures used in this study. Parents of all infants gave informed consent prior to testing. Participants in the ERP experiment were healthy, full-term infants. Twenty-seven 4-month-old (thirteen female) and twenty-five 8-month-old (thirteen female) infants were recruited from birth announcements in the St Paul/Minneapolis local area. Participants were paid $\$ 10$ and given a small toy for participation. All participants were Caucasian. Each participant completed either a configural change (twenty-five infants) or a featural change (twenty-seven infants) face task while ERPs were recorded from the scalp. Behavioral analyses were carried out on fifteen 8-montholds and twenty 4-month-olds from the larger sample. An additional fourteen infants (four in the 8-month-old group, and ten in the 4-month-old group) were excluded owing to significant left-side or right-side looking biases, and another six infants (four in the 8 -month-old group, and two in the 4-month-old group) were excluded owing to experimenter error.

3.1.2 Stimuli. The stimuli and conditions used in this experiment were the same as those used with the adults in experiment 1. Stimuli were presented with E-prime (version 1.0) software. For the ERP experiment, stimuli consisted of 60 pictures of each of 3 conditions, for a total of 180 randomly presented trials. The presentation of stimuli included the following: (i) the familiarized unchanged face, (ii) the familiarized face with either its features or its configuration altered, and (iii) a novel face (see figure 1). Infants varied in the number of trials completed; this variation was determined by differences in attention, and ability to stay on task. Once infants became fussy or tired, the experiment was ended. Infants 4 months old completed an average of 68 trials and infants 8 months old completed an average of 74 trials. Stimuli were presented for $500 \mathrm{~ms}$ and were only presented when the infant's eyes were fixated on the screen. All stimuli were presented on a blue screen. After each trial, a white fixation cross was presented until the infant's eyes were fixated on the screen. An experimenter sat next to the infant and redirected the infant's attention to the screen if necessary.

3.1.3 Behavioral visual paired-comparison methods. Prior to electrophysiological recording, infants completed a visual paired-comparison task. Infants were familiarized with an unfamiliar female face for an accumulated looking time of $20 \mathrm{~s}$ (familiarization time based on previous studies conducted in our lab; see Pascalis et al 2002). After this familiarization phase, infants were presented with 5-s side-by-side presentations of the familiarized face (unaltered) and the familiarized face with its configuration altered, followed by a 5 -s presentation of the familiarized face and the familiarized face with its features replaced. The order of presentation was counterbalanced across subjects and each pair 
of stimuli was presented twice, once on each side of the screen, to eliminate any looking biases infants may have (eg a preference for looking only to one side). Infants' looking times were recorded with a JVC TV and VCR and a Panasonic (WV-BP334) video camera. Visual preferences were computed as the percentage of looking time to the familiar and novel stimuli. Looking times were coded off-line by two different raters (blind to which side was familiar and which side was novel) with The Observer 5.0 (Noldus Information Technology, The Netherlands). Inter-rater reliability was coded for $15 \%$ of the subjects and was above $85 \%$ for each subject. $t$-Tests, corrected for multiple comparisons, were used to determine whether infants' looking to each stimulus was significantly above chance, ie 50\% $(p<0.05)$.

3.1.4 Electrophysiological methods. During ERP testing, infants within each age group either completed the configural or the featural task (between-subjects). Each task consisted of a habituation period, followed by test trials. Infants were habituated to a single unfamiliar female face, and then presented with a series of faces while ERPs were recorded. The habituation procedure was infant-controlled; infants viewed a single face until their last two consecutive looks were less than $50 \%$ of the average of the longest two consecutive looks. After the habituation phase, infants viewed serial presentations of stimuli including the following: (i) the familiarized face, (ii) the familiarized face with its either features or its configuration altered (between-subjects variable), and (iii) a novel or unfamiliar face.

ERPs were collected with a 64-channel Geodesic Sensor Net (Electrical Geodesics, Inc., Eugene, Oregon) connected to an AC-coupled 128-channel, high-input-impedance amplifier (Net Amps 200, Electrical Geodesics, Inc). Amplified analog voltages $(0.1-100 \mathrm{~Hz}$ bandpass) were digitized at $250 \mathrm{~Hz}$. Impedances were accepted if they were less than $50 \mathrm{k} \Omega$.

Post-recording segmentation and averaging was completed with Netstation 4.01 (Electrical Geodesics, Inc.). Trials were discarded from analyses if there were more than 10 bad channels (changing more than $75 \mu \mathrm{V}$ between samples or amplitudes in excess of $150 \mu \mathrm{V}$ ). Individual channels that were consistently bad (off-scale on more than $70 \%$ of the trials) were replaced by using a spherical interpolation algorithm. A mean of 4.27 channels were replaced with interpolated data per participant in 8-montholds and 7.34 channels in 4-month-olds.

Participants' ERPs were segmented and averaged to three different conditions for each group including featural task: (i) familiarized face, (ii) featural change, (iii) unfamiliar face; and configural task: (iv) familiarized face, (v) configural change, (vi) unfamiliar face. Difference waves were also computed by subtracting the waveform response of configural and featural changes from the familiarized face in each task. Participants with fewer than 15 artifact-free trials per condition were excluded from analyses (eleven 4-month-olds, four 8-month-olds). An average of 24 trials was included for each condition for 8-month-olds and 19 trials for 4-month-olds. ERPs were baseline corrected with respect to a $100-\mathrm{ms}$ pre-stimulus recording interval and were digitally low-pass filtered at $30 \mathrm{~Hz}$. An average reference was used to minimize the effects of referencesite activity and accurately estimate the scalp topography of ERPs recorded from a high-density electrode montage (Dien 1998). Epochs that captured components of interest were chosen on the basis of previous reports of the infant N290 and P400 (de Haan et al 2002) and on the basis of peak-amplitude measures across participants. Epochs were chosen to best reflect the component of interest within each age group and thus resulted in different time windows across ages.

\subsection{Results}

3.2.1 Behavioral results: 8-month-olds. Collapsing across both presentations (sides switched for looking biases) we found no significant preferences for familiar or novel presentations of either the configural or the featural changes. However, on separation into 
the first and second presentations, a significant familiarity preference emerged for the featural stimuli $\left(t_{14}=-2.23, p<0.05\right)$ in the first presentation, and a significant novelty preference emerged for the configural stimuli in the second presentation $\left(t_{14}=-2.45, p<0.05\right)$.

4-month-olds. Similarly, there were no significant preferences for familiar or novel presentations of either the configural or the featural changes in 4-month-olds. In addition, on separation into the first and second presentations, there were still no significant looking preferences for 4-month-olds.

3.2.2 Electrophysiological results. Analyses for the present study focused on the N290 and P400 components for both 4-month-old and 8-month-old groups.

N290 in 8-month-olds. For the N290, maximum negative amplitude and the corresponding latency were analyzed across conditions from 151 to $331 \mathrm{~ms}$ post-stimulus onset. The channels selected for analyses were determined on the basis of previous reports of the N290 with the EGI system (for example, see de Haan et al 2002) and by identifying the electrode locations within the occipital-temporal regions with prominent N290 and P400 components. Four electrodes from each hemisphere were then averaged (left: 32, 33, 36, and 37; right: 40, 41, 44, and 45). Analyses of overall effects and difference waves were conducted in the same manner as for experiment 1 . Only significant results are reported.

Analyses of the N290 did not reveal any significant differences in amplitude across all three conditions and groups. Latency analyses revealed a significantly longer latency to peak response for the familiarized face compared with the unfamiliar face $\left(F_{2,22}=3.23, p<0.05\right.$; see figure 4$)$ and a longer peak response in the right hemisphere than in the left hemisphere $\left(F_{1,23}=6.16, p<0.05\right.$; see table 2 and figure $\left.5 \mathrm{a}\right)$. Difference-wave analyses did not reveal any significant differences for this component.

P400 in 8-month-olds. For the P400, maximum positive amplitude and the corresponding latency were analyzed across conditions from 299 to $563 \mathrm{~ms}$ after stimulus onset. The same electrode groupings and analyses as those used for the analysis of the N290 were also used for the P400.

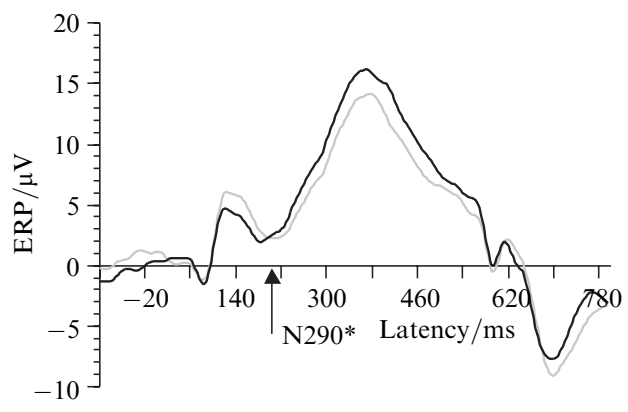

_ familiarized face — unfamiliar face

Figure 4. Experiment 2: Morphology of ERP waveform in 8-month-olds. There are significant latency differences between the familiarized and unfamiliar faces, regardless of group or hemisphere for the N290.

Maximum-amplitude analyses reveal greater amplitude in the left than in the right hemisphere across all conditions $\left(F_{1,23}=9.24, p<0.01\right.$; see figure 5a). Furthermore, significant interactions between hemisphere and group $\left(F_{1,23}=4.09, p<0.05\right)$ and between condition, hemisphere, and group $\left(F_{2,22}=6.42, p<0.01\right)$ were found. The interaction between hemisphere and group was due to a greater amplitude response in the left hemisphere than in the right hemisphere for the featural but not the configural group $\left(t_{12}=4.71, p<0.01\right.$; see table 3 and figure $\left.5 \mathrm{~b}\right)$. As indicated in table 4, follow-up analyses suggest that the three-way interaction occurs because of a greater maximumamplitude P400 response in the left hemisphere than in the right hemisphere in the featural task for the unfamiliar $\left(t_{12}=3.21, p<0.01\right)$ and familiar faces $\left(t_{12}=5.62\right.$, $p<0.01)$, and in the configural task for the familiar face $\left(t_{11}=2.49, p<0.05\right)$. 
Table 2. Significant main effects (means with standard errors in parentheses) for the N290, and P400 in 8-month-old infants.

\begin{tabular}{|c|c|c|c|c|c|c|c|}
\hline \multirow[t]{2}{*}{ Component } & \multicolumn{2}{|l|}{ Group } & \multicolumn{3}{|c|}{ Condition Hemisphere } & \multirow[b]{2}{*}{ left } & \multirow[b]{2}{*}{ right } \\
\hline & featural & configural & $\begin{array}{l}\text { altered } \\
\text { familiar } \\
\text { face }\end{array}$ & $\begin{array}{l}\text { familiar } \\
\text { face }\end{array}$ & $\begin{array}{l}\text { unfamiliar } \\
\text { face }\end{array}$ & & \\
\hline $\begin{array}{l}\mathrm{N} 290 \\
\text { maximum } \\
\quad \text { amplitude } / \mu \mathrm{V}\end{array}$ & $\begin{array}{l}-2.24 \\
(1.66)\end{array}$ & $\begin{array}{l}-2.75 \\
(1.73)\end{array}$ & $\begin{array}{l}-2.88 \\
(1.72)\end{array}$ & $\begin{array}{l}-2.34 \\
(1.02)\end{array}$ & $\begin{array}{l}-2.28 \\
(1.38)\end{array}$ & $\begin{array}{l}-2.99 \\
(1.39)\end{array}$ & $\begin{array}{l}-2.01 \\
(1.15)\end{array}$ \\
\hline $\begin{array}{l}\mathrm{N} 290 \\
\text { latency/ms }\end{array}$ & $\begin{array}{l}211.27 \\
(8.07)\end{array}$ & $\begin{array}{l}213.58 \\
(8.40)\end{array}$ & $\begin{array}{l}211.64 \\
(7.91)\end{array}$ & $\begin{array}{l}222.12 \\
(7.50)\end{array}$ & $\begin{array}{l}203.51 \\
(5.57)^{*}\end{array}$ & $\begin{array}{l}205.89 \\
(6.23) *\end{array}$ & $\begin{array}{l}218.96 \\
(6.56) *\end{array}$ \\
\hline $\begin{array}{l}\text { P400 } \\
\text { maximum } \\
\quad \text { amplitude } / \mu \mathrm{V}\end{array}$ & $\begin{array}{l}16.35 \\
(1.92)\end{array}$ & $\begin{array}{l}18.39 \\
(2.01)\end{array}$ & $\begin{array}{l}16.46 \\
(1.65)\end{array}$ & $\begin{array}{l}16.62 \\
(1.73)\end{array}$ & $\begin{array}{l}19.04 \\
(1.73)\end{array}$ & $\begin{array}{l}18.57 \\
(1.36) * *\end{array}$ & $\begin{array}{l}16.18 \\
(1.53)^{* * *}\end{array}$ \\
\hline $\begin{array}{l}\mathrm{P} 400 \\
\text { latency/ms }\end{array}$ & $\begin{array}{l}401.35 \\
(9.10)\end{array}$ & $\begin{array}{l}396.10 \\
(9.48)\end{array}$ & $\begin{array}{l}404.93 \\
(10.27)\end{array}$ & $\begin{array}{l}395.45 \\
(7.04)\end{array}$ & $\begin{array}{l}396.63 \\
(8.17)\end{array}$ & $\begin{array}{l}401.61 \\
(6.78)\end{array}$ & $\begin{array}{l}395.83 \\
(7.60)\end{array}$ \\
\hline
\end{tabular}

\section{- left hemisphere} right hemisphere

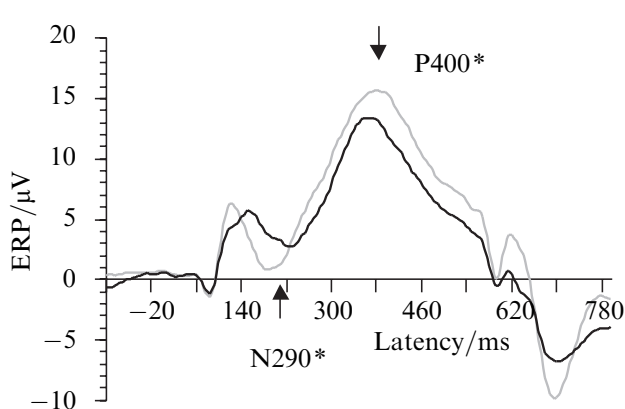

(a)

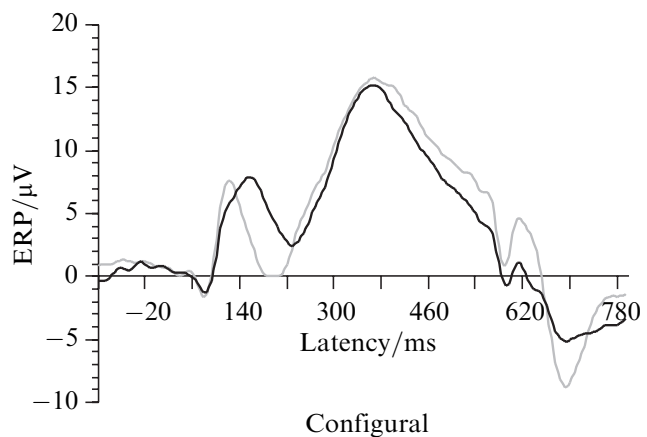

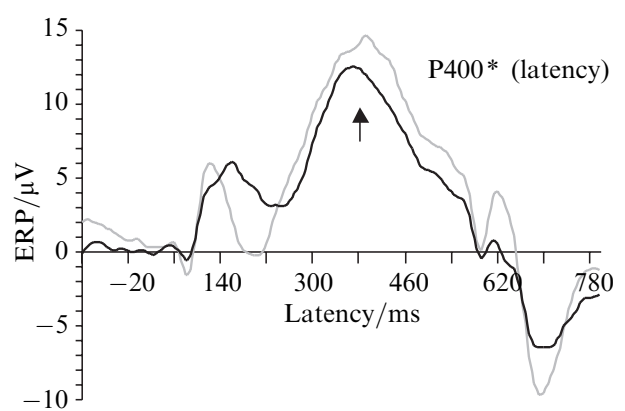

(c)

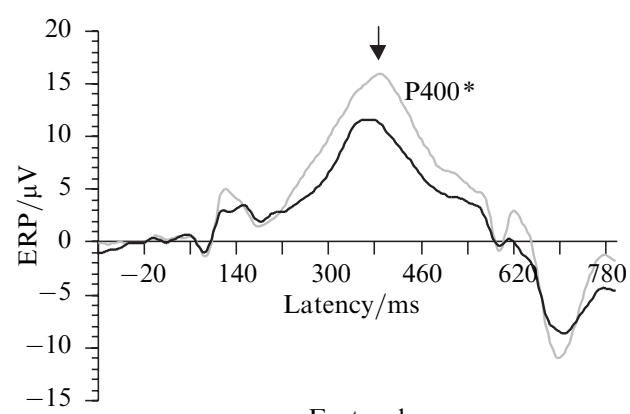

Featural

(b)

Figure 5. Experiment 2: Morphology of ERP waveform in 8-month-olds. There are significant differences across the left and right hemispheres (indicated by arrows): (a) overall, (b) configural versus featural, (c) altered face combined. The left hemisphere graph represents an average of electrodes: 32, 33, 36, and 37 across both the configural and featural change groups. The right hemisphere graph represents an average of electrodes: 41, 45, 40, and 44. Please note amplitude scale differences. 
Table 3. Significant two-way interactions (means with standard errors in parentheses) for the N290, and P400 in 8-month-old infants.

\begin{tabular}{|c|c|c|c|c|}
\hline Component & Interaction & Condition 1 & Condition 2 & Mean (SE) \\
\hline $\begin{array}{l}\mathrm{P} 400 \\
\text { maximum } \\
\text { amplitude } / \mu \mathrm{V}\end{array}$ & $\begin{array}{l}\text { group } \times \\
\text { hemisphere }\end{array}$ & $\begin{array}{l}\text { featural } \\
\text { configural }\end{array}$ & $\begin{array}{l}\text { left hemisphere } \\
\text { right hemisphere } \\
\text { left hemisphere } \\
\text { right hemisphere }\end{array}$ & $\begin{array}{l}18.33(\mathbf{1 . 8 8}) * \\
14.37(\mathbf{2 . 1 2}) * \\
18.79(1.96) \\
17.99(2.20)\end{array}$ \\
\hline $\begin{array}{l}\text { P400 } \\
\text { latency/ms }\end{array}$ & $\begin{array}{l}\text { condition } \times \\
\text { hemisphere }\end{array}$ & $\begin{array}{l}\text { familiar } \\
\text { altered face } \\
\text { unfamiliar face } \\
\text { familiar face }\end{array}$ & $\begin{array}{l}\text { left hemisphere } \\
\text { right hemisphere } \\
\text { left hemisphere } \\
\text { right hemisphere } \\
\text { left hemisphere } \\
\text { right hemisphere }\end{array}$ & $\begin{array}{l}413.95(\mathbf{1 1 . 4 0 )} * \\
\mathbf{3 9 4 . 2 3}(\mathbf{1 0 . 1 2 )} * \\
391.40(7.73) \\
401.38(10.65) \\
398.98(8.226) \\
391.90(8.72)\end{array}$ \\
\hline
\end{tabular}

$*$ and bold denotes significant differences $(*=p<0.05$; ** $p<0.01$; follow-up $t$-tests corrected for multiple comparisons).

Table 4. Significant three-way interactions (means and standard errors in parentheses) for the N290, and P400 in 8-month-old infants.

\begin{tabular}{|c|c|c|c|c|c|}
\hline Component & Interaction & Group & Condition & Hemisphere & Mean (SE) \\
\hline \multirow{12}{*}{$\begin{array}{l}\mathrm{P} 400 \\
\text { maximum } \\
\text { amplitude } / \mu \mathrm{V}\end{array}$} & \multirow{12}{*}{$\begin{array}{l}\text { group } \times \\
\text { condition } \times \\
\text { hemisphere } * *\end{array}$} & \multirow[t]{6}{*}{ featural } & familiar & left & $18.09(2.25)$ \\
\hline & & & altered face & right & $16.25(2.54)$ \\
\hline & & & unfamiliar & left & $20.37(2.66) *$ \\
\hline & & & & right & $15.00(2.48) *$ \\
\hline & & & familiar & left & $16.56(2.36) *$ \\
\hline & & & & right & $11.89(2.52) *$ \\
\hline & & \multirow[t]{6}{*}{ configural } & familiar & left & $17.15(2.34)$ \\
\hline & & & altered face & right & $14.33(2.65)$ \\
\hline & & & unfamiliar & left & $18.87(2.77)$ \\
\hline & & & & right & $21.97(2.59)$ \\
\hline & & & familiar & left & $20.35(2.45) *$ \\
\hline & & & & right & $17.68(2.63) *$ \\
\hline
\end{tabular}

$*$ and bold denotes significant differences $(*=p<0.05 ; * * p<0.01$; follow-up $t$-tests corrected for multiple comparisons).
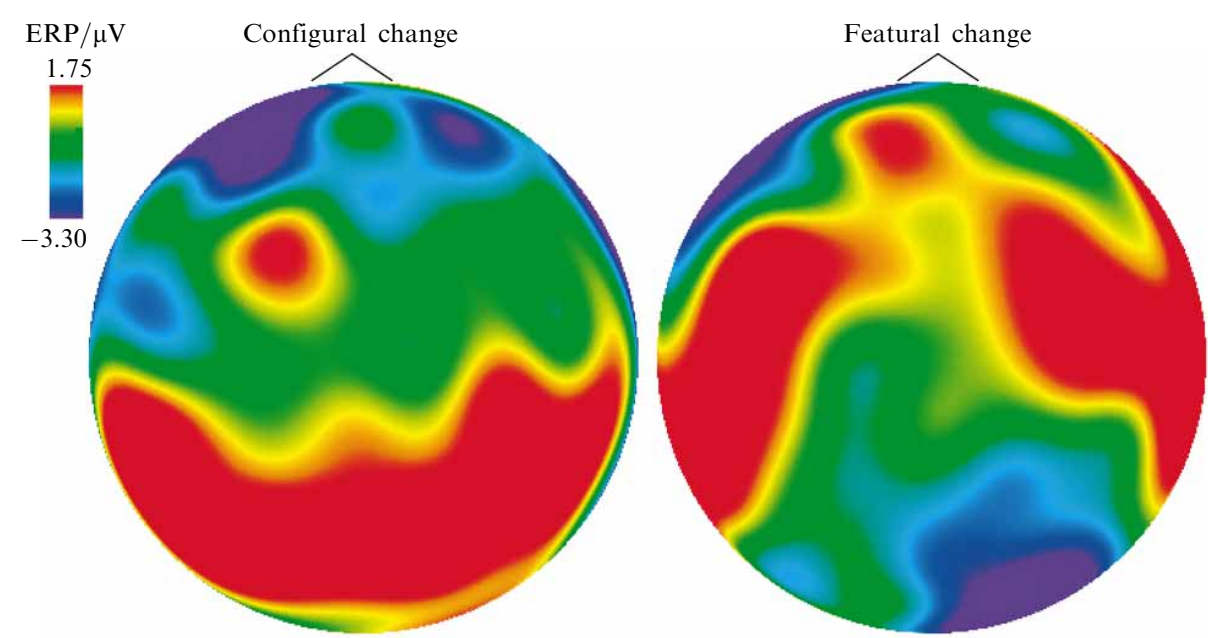

Figure 6. Experiment 2: Topographic differences between configural and featural changes for the P400 in 8-month-olds. Topographic maps represent the difference between the original familiarized face and either the featural or configural change faces. 
Difference-wave analyses of the maximum-amplitude response for the $\mathrm{P} 400$ reveal a significant hemisphere $\times$ group interaction $\left(F_{1,23}=4.51, p<0.05\right)$. This interaction is due to a greater difference in the left hemisphere than in the right hemisphere for the infants who completed the featural-change task $\left(t_{12}=2.29, p<0.05\right)$, but not for the configural-change task. In addition, a greater difference was also observed between the original familiar face and the configurally changed face compared to the featurally changed face in the right hemisphere $\left(t_{11}=-2.78, p<0.05\right)$. These effects are illustrated in figure 6 and table 5.

Table 5. Significant main effects (means and standard errors in parentheses) for the maximum difference-wave amplitude measures for P400 in 8-month-old infants.

Difference Left hemisphere Right hemisphere

\begin{tabular}{lcr}
\hline Featural $/ \mu \mathrm{V}$ & $-1.0(2.43)^{*}$ & $-4.24(1.98)^{*}, * *$ \\
Configural $/ \mu \mathrm{V}$ & $2.42(2.42)$ & $2.75(2.06)^{* *}$
\end{tabular}

$* p<0.05$ (single asterisk denotes comparisons between configural and featural conditions within hemispheres); $p<0.01$ (double asterisk comparisons across hemispheres within a condition).

Latency analyses reveal a significant interaction between condition and hemisphere $\left(F_{2,22}=4.32, p<0.05\right)$. As evident in figure $5 \mathrm{c}$ and table 3 , this interaction is due to a longer latency to peak response in the left hemisphere than in the right hemisphere for the altered face (either featural or configural: $t_{24}=3.07, p<0.01$ ). This latency difference was not found for the unfamiliar face or the familiarized face.

N290 in 4-month-olds. For the N290, maximum negative amplitude and latency were analyzed across conditions from 187 to $256 \mathrm{~ms}$ after stimulus onset. This window differs from that of 8 -month-olds because the peak of the component occurs later in 4-month-olds than in 8-month-olds. The channels selected and analyses conducted for this component were the same as for the 8-month-olds. Results of the amplitude and latency reveal no significant main effects or interactions across groups and conditions. There were no significant differences for measures of maximum negative amplitude, the corresponding latency, or for the difference-wave analyses.

P400 in 4-month-olds. For the P400, maximum amplitude and peak latency were analyzed across conditions from 227 to $699 \mathrm{~ms}$ after stimulus onset. The same electrode groupings and analyses as those used for the analysis of the P400 in 8-month-olds were also used for the P400 in 4-month-olds.

Analyses of maximum amplitude indicate a significantly greater amplitude response to the unfamiliar than to the altered and familiarized faces across groups and hemispheres $\left(F_{2,24}=4.90, p<0.05\right.$; see figure 7 and table 6$)$. There were no significant latency or difference-wave effects for this component (see table 7).

\subsection{Discussion}

The present study was designed to elucidate the electrophysiological and behavioral correlates of featural and configural processes in 8-month-old and 4-month-old infants. Two main hypotheses were proposed. First, it was hypothesized that 8-month-olds would show behavioral discrimination of both configural and featural face changes, but that 4-month-olds would be sensitive to only featural changes. Second, it was predicted that the infant N290 and P400, similar to the adult N170, would be sensitive to changes in featural and configural face information in 8-month-olds, and to featural information only in 4-month-olds.

Behavioral results suggest that 8-month-olds exhibited partial discrimination of both the featural and configural changes. However, these results were only evident when the 4 separate test trials were examined individually. Featural changes were discriminated 

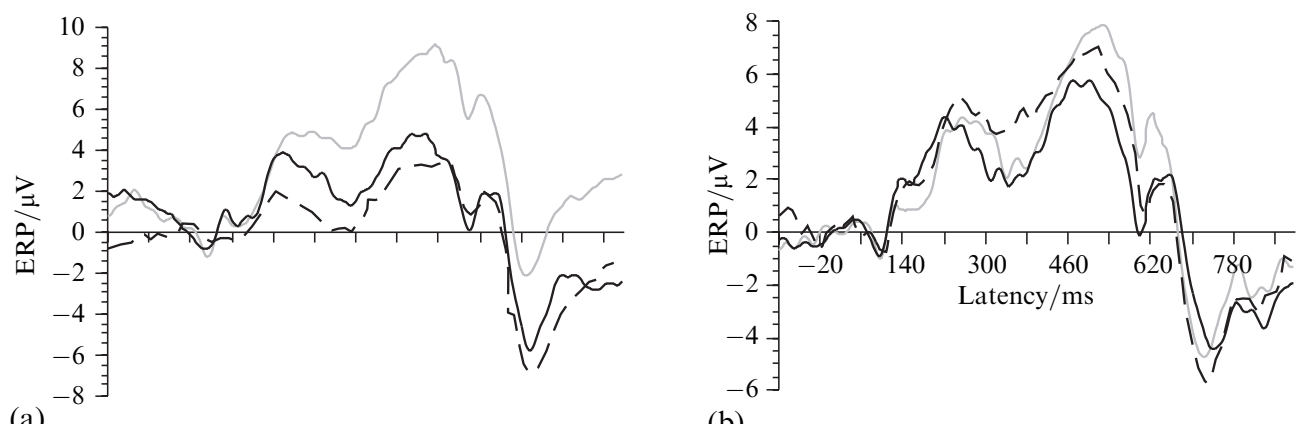

(b)
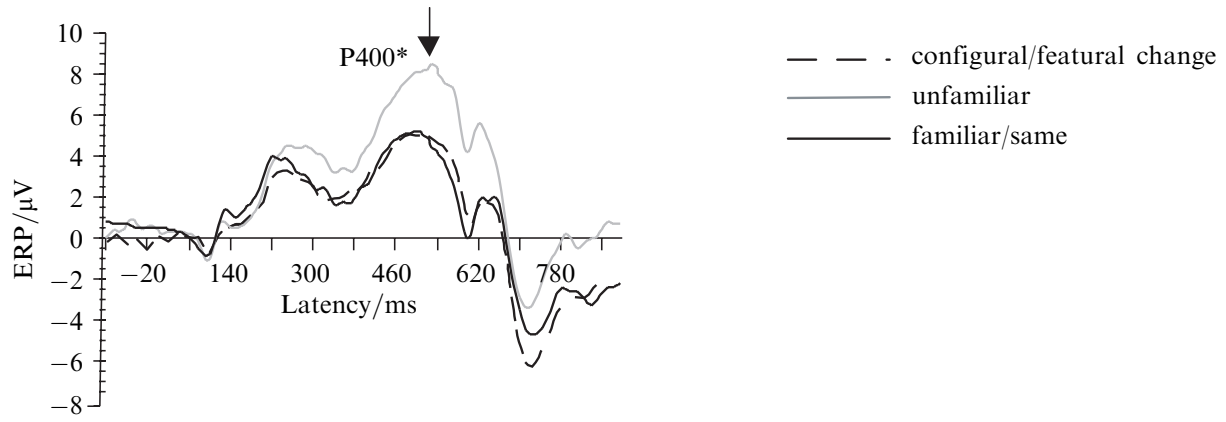

(c)

Figure 7. Morphology of ERP waveform in 4-month-olds: (a) configural; (b) featural; (c) combined. Plot (c) showing the combined effect depicts significant differences for the P400 component, collapsed across groups, and hemispheres. Please note amplitude scale differences.

Table 6. Significant main effects (means and standard errors) for the N290, and P400 in 4-month-olds.

\begin{tabular}{|c|c|c|c|c|c|c|c|}
\hline \multirow[t]{2}{*}{ Component } & \multicolumn{2}{|l|}{ Group } & \multicolumn{3}{|c|}{ Condition Hemisphere } & \multirow[b]{2}{*}{ left } & \multirow[b]{2}{*}{ right } \\
\hline & featural & configural & $\begin{array}{l}\text { altered } \\
\text { familiar } \\
\text { face }\end{array}$ & $\begin{array}{l}\text { familiar } \\
\text { face }\end{array}$ & $\begin{array}{l}\text { unfamiliar } \\
\text { face }\end{array}$ & & \\
\hline $\begin{array}{l}\mathrm{N} 290 \\
\text { maximum } \\
\quad \text { amplitude } / \mu \mathrm{V}\end{array}$ & $\begin{array}{l}-2.47 \\
(1.03)\end{array}$ & $\begin{array}{l}-3.85 \\
(1.07)\end{array}$ & $\begin{array}{l}-3.67 \\
(0.91)\end{array}$ & $\begin{array}{l}-3.19 \\
(1.04)\end{array}$ & $\begin{array}{l}-2.59 \\
(0.828)\end{array}$ & $\begin{array}{l}-2.92 \\
(0.82)\end{array}$ & $\begin{array}{l}-3.38 \\
(0.83)\end{array}$ \\
\hline $\begin{array}{l}\mathrm{N} 290 \\
\text { latency/ms }\end{array}$ & $\begin{array}{l}302.69 \\
(15.19)\end{array}$ & $\begin{array}{l}288.01 \\
(15.77)\end{array}$ & $\begin{array}{l}298.23 \\
(12.82)\end{array}$ & $\begin{array}{l}297.84 \\
(12.73)\end{array}$ & $\begin{array}{l}289.97 \\
(13.10)\end{array}$ & $\begin{array}{l}294.02 \\
(9.81)\end{array}$ & $\begin{array}{l}296.69 \\
(13.59)\end{array}$ \\
\hline $\begin{array}{l}\mathrm{P} 400 \\
\text { maximum } \\
\quad \text { amplitude } / \mu \mathrm{V}\end{array}$ & $\begin{array}{l}11.53 \\
(1.31)\end{array}$ & $\begin{array}{l}12.73 \\
(1.36)\end{array}$ & $\begin{array}{l}11.18 \\
(1.08)\end{array}$ & $\begin{array}{l}11.37 \\
(1.05)\end{array}$ & $\begin{array}{l}13.84 \\
(1.17)^{*}\end{array}$ & $\begin{array}{l}12.12 \\
(0.83)\end{array}$ & $\begin{array}{l}12.14 \\
(1.25)\end{array}$ \\
\hline $\begin{array}{l}\mathrm{P} 400 \\
\text { latency/ms }\end{array}$ & $\begin{array}{l}445.93 \\
(23.03)\end{array}$ & $\begin{array}{l}466.90 \\
(23.87)\end{array}$ & $\begin{array}{l}443.34 \\
(21.70)\end{array}$ & $\begin{array}{l}453.98 \\
(18.94)\end{array}$ & $\begin{array}{l}471.92 \\
(16.49)\end{array}$ & $\begin{array}{l}453.58 \\
(18.70)\end{array}$ & $\begin{array}{l}459.25 \\
(16.62)\end{array}$ \\
\hline
\end{tabular}

Table 7. Significant main effects (means and standard errors in parentheses) for the maximum difference-wave amplitude measures for P400 in 4-month-old infants.

\begin{tabular}{lrr}
\hline Difference & Left hemisphere & Right hemisphere \\
\hline Featural $/ \mu \mathrm{V}$ & $-0.15(1.43)$ & $-0.75(1.72)$ \\
Configural $/ \mu \mathrm{V}$ & $0.38(1.49)$ & $1.60(1.78)$ \\
(all comparisons are non-significant) &
\end{tabular}


as evidenced by a familiarity preference in the first, but not second presentation of the featural comparison. In contrast, configural changes were discriminated, as evidenced by a significant novelty preference, in the second, but not the first, presentation of the stimuli.

In contrast to the 8-month-olds, 4-month-olds did not exhibit discrimination across either condition for any of the VPC trials. Combined, these results suggest that 8-montholds may have an increased ability to discriminate both configural and featural face changes compared to 4-month-olds. However, this interpretation must be made with caution, as a null result is often difficult to interpret and the lack of a looking preference alone does not necessarily mean that there was no discrimination (Sophian 1980). It could simply mean that 4-month-olds may need a longer familiarization time to fully encode these stimuli compared to 8-month-olds (Hunter et al 1983; Hunter and Ames 1988; Courage and Howe 1998). Nevertheless, in light of the results for 8-month-olds, these data do suggest that 8-month-olds may have an increased ability to discriminate both types of face changes compared to 4-month-olds, under the present circumstances. It is difficult to make sense of the direction of preference and early versus late discrimination across conditions in 8-month-olds. A novelty preference is thought to facilitate adaptation to a constantly changing environment (Sokolov 1963). Thus, it is adaptive for infants to orient and attend to novel events in their environments. However, as Sophian (1980) points out, significant familiarity preferences are also evidence of recognition memory and discrimination. Additionally, if the stimulus is not fully encoded, a familiarity preference is actually expected (Richards 1997; for review see Courage and Howe 1998). Thus, it is plausible that infants are still encoding the familiar stimulus during the test trials, resulting in an early familiarity preference for the featurally changed faces and, once encoded, a later novelty preference for the configurally changed face. One possible interpretation of these data is that featural changes are more difficult to detect than configural changes in 8-month-olds. This interpretation is consistent with the development of the visual system. More specifically, contrast sensitivity, acuity, and the ability to resolve high-spatial-frequency information (all important factors for differentiating features) develop later than the ability to resolve low-spatial-frequency information (important in detecting configuration differences; see de Schonen and Mathivet 1990; Simion et al 1998). Thus, if the ability to utilize high spatial frequency is still developing, it is conceivable that detecting featural changes would be more difficult than detecting configural changes. Further research is required to clarify these findings, in particular the 8-month-old preferences across some, but not all, trials and the direction of these preferences across conditions. Moreover, there were large individual differences across infants that need to be further investigated. Most infants in this study appear to show a significant preference, but the direction of this preference is bimodally distributed with half of the infants showing novelty preferences, half showing familiarity preferences, and a few with no preferences.

Overall, the electrophysiological results suggest that 8-month-olds have a more specialized and more adult-like response to faces than 4-month-olds. In 8-month-olds, the latency of the N290 component was longer in the right hemisphere than in the left hemisphere. Furthermore, the latency response to the familiarized face is significantly longer than to an unfamiliar face. In comparison, there were no significant differences across conditions, groups, and hemispheres for the N290. For the P400 component, 8-month-olds had a greater amplitude response in the left hemisphere than in the right hemisphere. This difference was most prominent in the featural condition for the unfamiliar and familiar faces and in the configural condition for the familiarized face. There was no hemispheric differences for the P400 in 4-month-old infants. Furthermore, the P400 in the 8-month-olds peaked significantly later in the 
left than in the right hemisphere for the altered face (regardless of whether the change was featural or configural). Interestingly, the P400 in 4-month-olds was greater for the unfamiliar than for the familiarized and altered familiarized faces (regardless of group). This finding partially supports the original hypothesis that 4-month-olds would have more difficulty discriminating configural changes. However, this sensitivity does not differ across featural and configural groups. The sensitivity to familiar stimuli may be similar to the latency differences found in the N290 of the 8-month-olds.

An examination of the difference-wave results reveals very interesting results. The 8-month-olds, similar to what was previously reported in adults, exhibited greater left than right hemisphere differences when comparing the featural change to the configural change, and in the right hemisphere there was a greater difference between the configural change and the original face compared to the featural change and the original face. This similarity between adults and 8-month-olds will be discussed further in the general discussion (section 4). In contrast, the difference-wave analyses in the 4-montholds did not reveal any significant differences.

Combined, the behavioral and electrophysiological results from the current study suggest that, unlike 4-month-olds, 8-month-olds exhibited precursors to adult-like face processing. These results are somewhat inconsistent with what Cashon and Cohen (2004) report. In contrast to the present study, these authors reported that 4-monthold infants are able to detect changes in the inner and outer features of the face. However, in the current investigation both electrophysiological and behavioral data suggest that 4-month-olds are not able to detect configural or featural face changes. One important difference between the two reports is that the featural and the configural manipulations in the two studies were very different. Cashon and Cohen examined infants' ability to detect changes between the inner and outer parts of the head. More specifically, they replaced the entire set of unchanged features within a face, but left the contour (outer edge of the face and hair) unchanged. According to Mondloch et al (2002) detecting this type of contour reaches adult levels before the ability to detect second-order (spacing between eyes, etc) changes in faces. In the present investigation we made changes to the eyes and the mouth, and in both the featuralchange and configural-change conditions the contour and the rest of the face remained the same. Thus, the detection of second-order configural and featural face changes may follow a different (protracted) developmental trajectory compared to that of contour detection.

The results of this experiment provide further evidence that the infant P400 component is a precursor to the adult N170 face component. At this time, further research is needed to explain the development of the face-processing components in infancy and explain why (and how), for example, processing faces appears to functionally shift from a positive to a negative component with development. There are several possible explanations for this, including cortex maturation, and increases in speed of processing which result in a functional shift.

The present investigation also provides both behavioral and electrophysiological support for differential processing of featural and configural face changes from 4 to 8 months of age. However, these results are not consistent with the hypothesis that there is a developmental shift from more featural-based to configural-based face processing from 4 to 8 months of age, and may actually suggest the opposite, on the basis of the development of the ability to use high-spatial-frequency and low-spatial-frequency information. The relation between configural and featural processing and the development of high-spatial-frequency and low-spatial-frequency utilization should be further investigated. 


\section{General discussion}

The goals of the present set of experiments were twofold. The first experiment was intended to elucidate the electrophysiological correlates of configural and featural face processing in adults. More specifically, this study was designed to discern whether the N170 face component was sensitive to these different types of changes and, if so, how these changes were distributed across the scalp. The second experiment, based on previous reports about developmental differences in configural and featural processing, was designed to test whether there are behavioral or electrophysiological differences between configural and featural processing in infants aged 4 and 8 months.

The electrophysiological results of the study for the adults provide compelling evidence against the notion that the adult N170 face component is simply a 'face detector' (Bentin et al 1996; Bentin and Deouell 2000; Sagiv and Bentin 2001; Carmel and Bentin 2002). Moreover, these data do not support the idea that the N170 is only sensitive to first-order spatial relations (something 'face-like'), and suggest that this component may also be sensitive to second-order relations (or changes in spatial layout-Maurer et al 2002). These data imply that, similar to what has been reported with non-face objects (Egly et al 1994; Akshoomoff et al 2002), the left hemisphere is more sensitive to the detection of featural face changes, whereas both the left and right hemispheres are sensitive to configural face changes. Moreover, the N170 response in the current investigation is greater in the left hemisphere for featural changes and greater in the right hemisphere for configural changes. These results indicate differential neural processing of featural and configural changes across hemispheres, with greater overlap for configural changes.

The results from the experiment with infants suggest developmental differences in the ability to detect both configural and featural face changes from 4 to 8 months of age. Behaviorally, 8-month-olds have a somewhat increased ability to discriminate such changes than 4-month-olds. One of the most striking findings from this set of experiments is the similar pattern of electrophysiological results when comparing the 8-month-olds to the adults. Both age groups exhibited very similar results for the difference waves (subtracting responses to the altered familiarized faces from that of the familiarized faces). The pattern of results for the P400 in 8-month-olds almost mirrors the pattern of results for the N170 in adults. Both components were greater in amplitude to the featural changes in the left than in the right hemisphere, were equal in amplitude to the configural changes across both hemispheres, and in the right hemisphere the configural change elicited a response with greater amplitude than did the featural changes. The primary difference between the two age groups was that part of the dissociation found in adults (greater amplitude to the featural than to the configural change in the left hemisphere) was not apparent for 8-month-olds (see tables 1 , 5, and 7 for a comparison of the difference-wave results across all age groups). These results are consistent with the view that the P400 is a developmental precursor to, or analog of, the N170 face component in adults, supporting previous reports that the P400 is similarly sensitive to changes in faces [ie peaks faster to faces than objects (de Haan and Nelson 1999) and sensitive to face inversion (de Haan et al 2002)].

In addition, these results indicate that infants as young as 8 months of age are sensitive to second-order configural changes in faces. These findings stand in contrast to several reports suggesting that adult-like configural face processing does not occur until early to late childhood (for example, Carey and Diamond 1977, 1994; Schwarzer 2000; Brace et al 2001). Furthermore, the results are consistent with the model of perceptual narrowing (Nelson 2001, 2003) in face processing. Although 4-month-olds do not have the same electrophysiological specificity as 8-month-olds when looking at the difference waves and hemispheric differences across conditions, the P400 results in 4-month-olds do suggest that they may have an increased ability to discriminate across 
conditions compared to 8-month-olds and adults (compare figures 8 and 7). Whereas the 8-month-olds and adults do not exhibit any main effects of condition for the N170 (adults) or the P400 (8-month-olds), the P400 of the 4-month-olds is significantly greater to the unfamiliar than to the familiar and altered familiar faces. Thus, if the P400 is a precursor to the N170 in adults, there is evidence that 4-month-olds have an increased sensitivity to familiar and unfamiliar faces as indexed by this component. Furthermore, these results suggest that the function and specificity of the N170 may change across development. For example, early in development the P400 component may be involved in individuating faces by detecting familiarity or novelty, but with further development this component becomes less sensitive to these types of face changes.

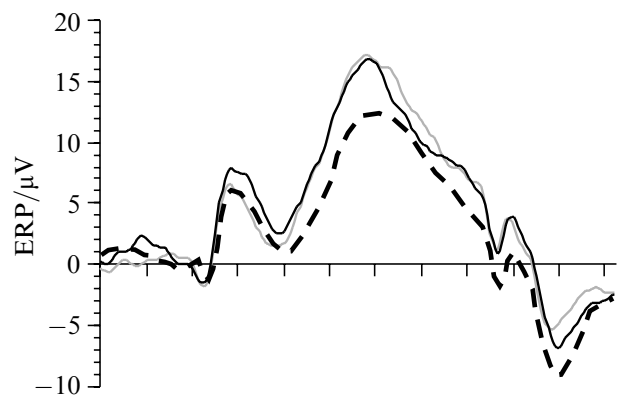

(a)

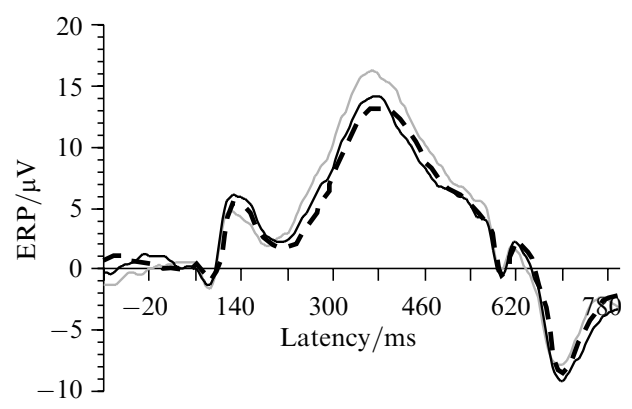

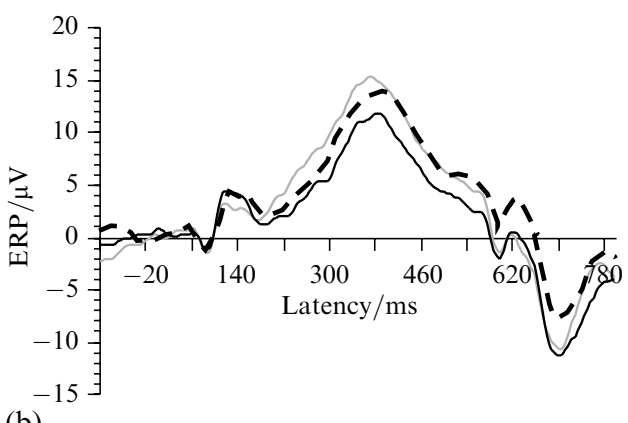

(b)

(c)

Figure 8. Morphology of ERP waveform in 8-month-olds: (a) configural; (b) featural; (c) combined. In comparison to figure 7, these results are non-significant. Please note amplitude scale differences.

Overall, the findings of the current set of investigations suggest developmental differences between 4-month-olds, 8-month-olds, and adults. These results suggest that the 8-month-olds and adults are surprisingly similar in their processing of featural and configural changes. Finally, as evidenced by the differences in the P400 between the infants, the P400 in 4-month-olds may differ in function compared to the N170 in adults, and the P400 in 8-month-olds.

Acknowledgments. This research was primarily funded by a doctoral dissertation fellowship and grant from the Graduate School at the University of Minnesota. It was also funded in part from a small research grant from the Institute of Child Development, a training grant provided by the National Institute of Child Health \& Human Development to the Center for Cognitive Sciences at the University of Minnesota (5T32 HD07151), and a grant to Charles A Nelson from the National Institute of Neurological Disorders and Strokes (NS32976). Support during the write-up and review of this manuscript came to the first author from the James S McDonnell foundation to the Perceptual Expertise Network. We thank Elizabeth Nicholson and Robert Shannon for help testing participants and coding videos, and Ruskin Hunt and Kathleen Thomas for theoretical and technical support. 


\section{References}

Akshoomoff N, Feroleto C C, Doyle R E, Stiles J, 2002 "The impact of early unilateral brain injury on perceptual organization and visual memory" Neuropsychologia 40 539-561

Bentin S, Allison T, Puce A, Perez E, McCarthy G, 1996 "Electrophysiological studies of face perception in humans" Journal of Cognitive Neuroscience 8551 - 565

Bentin S, Deouell L Y, 2000 "Structural encoding and identification in face processing: ERP evidence for separate mechanisms" Cognitive Neuropsychology 17 35-54

Brace N A, Hole G J, Kemp R I, Pike G E, Van Duuren M, Norgate L, 2001 "Developmental changes in the effect of inversion: Using a picture book to investigate face recognition" Perception $3085-94$

Carey S, Diamond R, 1977 "From piecemeal to configurational representation of faces" Science $195312-314$

Carey S, Diamond R, 1994 "Are faces perceived as configurations more by adults than by children?" Visual Cognition $1253-274$

Carmel D, Bentin S, 2002 "Domain specificity versus expertise: Factors influencing distinct processing of faces" Cognition $831-29$

Cashon C H, Cohen L B, 2004 "Beyond U-shaped development in infants' processing of faces: An information-processing account" Journal of Cognition and Development 5 59-80

Chance J E, Turner A L, Goldstein A G, 1982 "Development of differential recognition for own- and other-race faces" Journal of Psychology 112 29-37

Cohen L B, Cashon C H, 2001 "Do 7-month-old infants process independent features or facial configurations?" Infant and Child Development 1083 -92

Courage M L, Howe M, 1998 "The ebb and flow of infant attentional preferences: Evidence for long-term recognition memory in 3-month-olds" Journal of Experimental Child Psychology $7026-53$

Curran T, Tanaka J W, Weiskopf D M, 2002 "An electrophysiological comparison of visual categorization and recognition memory" Cognitive, Affective, \& Behavioral Neuroscience $21-18$

Dien J, 1998 "Issues in the application of the average reference: Review, critiques, and recommendations" Behavior Research Methods, Instruments, \& Computers 30 34-43

Deruelle C, Schonen S de, 1998 "Do the right and left hemispheres attend to the same visuo-spatial information within a face in infancy?" Developmental Neuropsychology 14123 - 132

Egly R, Driver J, Rafal R D, 1994 "Shifting visual attention between objects and locations: Evidence from normal and parietal lesion subjects" Journal of Experimental Psychology: General $123161-177$

Farah M J, 1995 "Face perception and within-category discrimination in prosopagnosia" Neuropsychologia $33661-674$

Farah M J, Wilson K D, Drain M, Tanaka J R, 1995 "The inverted face inversion effect in prosopagnosia: Evidence for mandatory, face-specific perceptual mechanisms" Vision Research $352089-2093$

Freire A, Lee K, Symons L, 2000 "The face-inversion effect as a deficit in the encoding of configural information: Direct evidence" Perception $29159-170$

Gauthier I, Curran T, Curby K M, Collins D, 2003 "Perceptual interference supports a nonmodular account of face processing" Nature Neuroscience $6428-432$

Gauthier I, Tarr M J, 1997 "Becoming a 'Greeble' expert: Exploring the face recognition mechanism" Vision Research $371673-1682$

Gelder B de, Bachoud-Levi A C, Degos J D, 1998 "Inversion superiority in visual agnosia may be common to a variety of orientation polarized objects besides faces" Vision Research $\mathbf{3 8}$ $2855-2861$

Haan M de, Johnson M H, Halit H, 2003 "Development of face sensitive event-related potentials during infancy: A review" Journal of Psychophysiology 51 45-58

Haan M de, Nelson C A, 1999 "Brain activity differentiates face and object processing by 6-month-old infants" Developmental Psychology 351113 - 1121

Haan M de, Pascalis O, Johnson M H, 2002 "Specialization of neural mechanisms underlying face recognition in human infants" Journal of Cognitive Neuroscience 12 199-209

Halit H, Haan M de, Johnson M H, 2003 "Cortical specialization for face processing: facesensitive event-related potential components in 3- and 12-month-old infants" NeuroImage 19 $1180-1193$

Haxby J V, Gobbini M I, Furey M L, Ishai A, Schouten J L, Pietro P, 2001 "Distributed and overlapping representations of faces and objects in ventral temporal cortex" Science 293 $2425-2430$ 
Hunter M, Ames E, 1988 "A multifactor model of infant preferences for novel and familiar stimuli", in Advances in Infancy Research volume 5, Eds S Rovee-Collier, L P Lipsitt (Norwood, NJ: Ablex) pp 69-95

Hunter M, Ames E, Koopman R, 1983 "Effects of stimulus complexity and familiarization time on infant preferences for novel and familiar stimuli" Developmental Psychology 19338 - 352

Jeffreys D A, 1996 "Evoked potential studies of face and object processing" Visual Cognition 3 $1-38$

Kanwisher N, McDermott J, Chun M M, 1997 "The fusiform face area: A module in human extrastriate cortex specialized for face perception" Journal of Neuroscience $174302-4311$

Kestenbaum R, Nelson C A, 1990 "The recognition and categorization of upright and inverted emotional expressions by 7-month-old infants" Infant Behavior and Development 13 497-511

Le Grand R, Mondloch C, Maurer D, Brent H P, 2001 "Early visual experience and face processing" Nature $\mathbf{4 1 0} 890$

Le Grand R, Mondloch C, Maurer D, Brent H P, 2003 "Expert face processing requires visual input to the right hemisphere during infancy" Nature Neuroscience $61108-1112$

McKone E, Martini P, Nakayama K, 2001 "Categorical perception of face identity in noise isolates configural processing" Journal of Experimental Psychology: Human Perception and Performance $27573-599$

Marotta J J, Genovese C R, Behrmann M, 2001 "A functional MRI study of face recognition in patients with prosopagnosia" NeuroReport $121581-1587$

Maurer D, Le Grand R, Mondloch C, 2002 "The many faces of configural processing" Trends in Cognitive Sciences $6255-260$

Mondloch C, Le Grand R, Maurer D, 2002 "Configural face processing develops more slowly than featural face processing" Perception $31553-566$

Murray J E, Rhodes G, Schuchinsky M, 2003 "When is a face not a face? The effects of misorientation on mechanisms of face perception", in Perception of Faces, Objects, and Scenes: Analytic and Holistic Processes Eds M A Peterson, G Rhodes (Oxford: Oxford University Press) pp $75-117$

Nelson C A, 2001 "The development and neural bases of face recognition" Infant and Child Development $103-18$

Nelson C A, 2003 "The development of face recognition reflects an experience-expectant and activity-dependent process", in The Development of Face Processing in Infancy and Early Childhood: Current Perspectives Eds O Pascalis, A Slater (New York: Nova Science) pp 79-97

Pascalis O, Haan M de, Nelson C A, 2002 "Is face processing species-specific during the first year of life?" Science 2961321 - 1323

Pascalis O, Scott L S, Kelly D J, Shannon R W, Nicholson E, Coleman M, Nelson C A, 2005 "Plasticity of face processing in infancy" Proceedings of the National Academy of Sciences of the USA $1025297-5300$

Renzi E de, Perani D, Carlesimo G A, Silveri M C, Fazio F, 1994 "Prosopagnosia can be associated with damage confined to the right hemisphere-an MRI and PET study and review of the literature" Neuropsychologia $32893-902$

Rhodes G, 1988 "Looking at faces: First-order and second-order features as determinants of facial appearance" Perception $1743-63$

Rhodes G, Brake D, Atkinson A P, 1993 "What's lost in inverted faces?" Cognition $4725-57$

Richards J, 1997 "Effects of attention on infants' preference for briefly exposed visual stimuli in the paired-comparison recognition-memory paradigm" Developmental Psychology $3322-31$

Rossion B, Delvenne J-F, Debatisse D, Goffaux V, Bruyer R, Crommelinck M, Guerit J-M, 1999 "Spatio-temporal localization of the face inversion effect: An event-related potentials study" Biological Psychology $50173-189$

Rossion B, Dricot L, Devolder A, Bodart J-M, Crommelinck M, Gelder B de, Zoontjes R, 2000 "Hemispheric asymmetries for whole-based and part-based face processing in the human fusiform gyrus" Journal of Cognitive Neuroscience 12 793-802

Rossion B, Gauthier I, Goffaux V, Tarr M J, Crommelinck M, 2002 "Expertise training with novel objects leads to left-lateralized facelike electrophysiological responses" Psychological Science $\mathbf{1 3}$ $250-257$

Sagiv N, Bentin S, 2001 "Structural encoding of human and schematic faces: Holistic and partbased processes" Journal of Cognitive Neuroscience 13 937-951

Schonen S de, Mathivet E, 1990 "Hemispheric asymmetry in a face discrimination task in infants" Child Development $611192-1205$

Schwarzer G, 2000 "Development of face processing: The effect of face inversion" Child Development $71391-401$ 
Sergent J, 1984 "An investigation into component and configural processes underlying face perception" British Journal of Psychology 75221 - 242

Simion F, Valenza E, Umiltà C, Dalla Barba B, 1998 "Preferential orienting to faces in newborns: a temporal-nasal asymmetry" Journal of Experimental Psychology: Human Perception and Performance 24 1399-1405

Sokolov E, 1963 Perception and the Conditioned Reflex (Oxford: Pergamon Press)

Sophian C, 1980 "Habituation is not enough: Novelty preferences, search, and memory in infancy" Merrill Palmer Quarterly $26239-257$

Tanaka J W, Curran T, 2001 "A neural basis for expert object recognition" Psychological Science $1243-47$

Tanaka J W, Kiefer M, Bukach C M, 2004 "A holistic account of the own-race effect in face recognition: Evidence from a cross-cultural study" Cognition 93 B1 - B9

Tanaka J W, Sengco J A, 1997 "Features and their configuration in face recognition" Memory and Cognition $25583-592$

Thompson P, 1980 "Margaret Thatcher: a new illusion" Perception $9483-484$

Yin R K, 1969 "Looking at upside-down faces” Journal of Experimental Psychology 81 141-145

Younger B A, Cohen L B, 1986 "Developmental change in infants' perception of correlations among attributes" Child Development $51221-242$ 


\section{PERCEPTION}

VOLUME 352006

www.perceptionweb.com

Conditions of use. This article may be downloaded from the Perception website for personal research by members of subscribing organisations. Authors are entitled to distribute their own article (in printed form or by e-mail) to up to 50 people. This PDF may not be placed on any website (or other online distribution system) without permission of the publisher. 